\title{
Community participation in mitigating marine waste to reduce climatic change in tourism destinations
}

\begin{abstract}
Purpose: Waste in the marine environment has become a serious task to be managed. Uncontrolled dumping creates large amounts of methane gas contributing to greenhouse gas emissions. This conceptual paper focuses on the role of community in waste management activities to reduce carbon emissions in the marine environment. Hence, this paper aims to examine using literature, the various roles of community, types of marine waste and its impact on carbon emissions and climate change.
\end{abstract}

Design/methodology/approach: The paper is based on evaluation and criticism from previous studies and provides a hypothetical understanding of the human contribution to climate change, and its impacts which will increasingly affect climate change and sustainable tourism.

Findings: The results from this study can be used as a guide for policy makers to help improve community participation and public engagement in efforts to reduce the levels of waste in the marine environment. This is especially critical in rural tourism destinations where the impact of uncontrolled marine waste has serious consequences for the tourism industry.

Originality/value: The paper contributes to a better understanding of the role of community in mitigating waste to attain a higher quality of tourism experience and environmental benefits from emission level reductions.

Keyword: $\quad$ Tourism; Carbon emission; Community participation; Marine waste 